\title{
Mujer-vida-libertad. Participación de las mujeres en el proyecto económico/ecológico de la Federación Democrática del norte de Siria-Rojava ${ }^{1}$

\author{
Woman-Life-Freedom. Women's participation in the Economic/Ecological Project \\ of the Democratic Federation of Norther Syria-Rojava
} \\ Erika S. AGUILAR SILVA \\ Universidad Nacional Autónoma de México \\ erika.aguilar@politicas.unam.mx \\ https://orcid.org/0000-0002-9001-9981 \\ Recibido 03/09/2019. Revisado y aceptado para publicación 13/12/2019
}

Para citar este artículo: Erika S. AGUILAR SILVA (2019), “Mujer-vida-linertad. Participación de las mujeres en el proyecto económico/ecológico de la Federación Democrática del norte de Siria-Rojava" en Revista de Estudios Internacionales Mediterráneos, 27, pp. 150-169.

Para acceder a este artículo: https://doi.org/10.15366/reim2019.27.010

\section{Resumen}

Bajo los principios de la ecología social, el confederalismo democrático ha propiciado que las mujeres que participan en él consideren ineludible su adscripción al sistema de comunas y cooperativas a través de las cuales se está creando un modelo sustentable de producción y, hasta ahora, lo que consideran como el logro más representativo de este proceso, es decir, Jinwar, la única aldea ecológica de mujeres. A pesar de ello, el proyecto económico/ecológico de Rojava también enfrenta una serie de dificultades que ponen en peligro su subsistencia.

Palabras clave: ecología social/ mujeres/ cooperativas/ Jinwar/

Abstract

Following the principles of social ecology, Democratic Confederalism has led its women participants essentially to consider their membership in the system of communes and cooperatives. On it, they see one important and sustainable production model and, so far, the most representative achievement of this process, this is, the creation of Jinwar, the only ecological village of women. Despite this, the economic/ecological project of Rojava also faces a series of difficulties that endanger its subsistence.

Keywords: Social ecology/ women/ cooperatives/ Jinwar/

\footnotetext{
${ }^{1}$ Este artículo ha sido posible gracias al apoyo del PAPIIT IN305119 "Sectarismo y Justicia Social en el Medio Oriente del siglo XXI financiado por la DGAPA".
} 
Una sociedad no puede ser democrática con respecto a las minorías etnorreligiosas ni ser verdaderamente progresista en materia de género si no puede, en primer lugar, demostrar un respeto integral y profundo por nuestra tierra común. Hawzhin Azeez

\section{Introducción}

De los tres pilares ${ }^{2}$ que sostienen el confederalismo democrático de la Federación Democrática del norte de Siria (FDNS) ${ }^{3}$-Rojava, la cuestión ecológica es probablemente el que menos se ha problematizado pese a lo crucial que resulta para la concreción total del proyecto. Así como el autoritarismo del régimen sirio ha desconocido la identidad y los derechos de la población kurda y ha utilizado la violencia de género para cooptar sus reivindicaciones económicas, sociales y políticas, también ha implementado una serie de prácticas de saqueo y explotación que, bajo el pretexto del desarrollo y el progreso, terminaron por dañar gravemente la tierra y el resto del entorno natural. Esta situación supone, entre otros, uno de los más grandes retos del confederalismo democrático ${ }^{4}$.

Para los habitantes de Rojava, como para tantos otros pueblos originarios alrededor del mundo, la conexión con el territorio se basa en una cosmovisión totalmente opuesta al antropocentrismo y, por lo tanto, comprende aspectos espirituales, ideológicos, identitarios ${ }^{5}$ e incluso constituye el

\footnotetext{
${ }^{2}$ A saber: sociedad autónoma y democrática, equidad de género y sostenibilidad ecológica.
}

${ }^{3}$ El escenario al que nos referiremos en el presente escrito ha cambiado de nombre en varias ocasiones. Su denominación más reciente fue adoptada en septiembre del año 2018, cuando el Consejo Democrático Sirio (creado en diciembre del año 2015 para la implementación de un sistema federal) lo denominó Administración Autónoma del norte y este de Siria. Pese a esta actualización, en el texto se utilizará indistintamente "Rojava" ("occidente" en kurdo) por ser la denominación más popular (aunque en la región habiten también armenios, árabes, asirios, caldeos, turcomanos, etc.) o "FDNS" dado que es así como figura en el Contrato Social de diciembre de 2016, documento que describe los objetivos y funcionamiento de dicha administración (el primer Contrato Social fue dado a conocer en enero de 2014 y hacía mención a las "regiones autónomas democráticas de Cizire, Kobane y Afrin"). Conviene señalar que es al Contrato del año 2016 al que habrá que remitirse cuando se mencione alguna de sus disposiciones.

4 Adicionalmente, cabe mencionar que este proyecto se ha desarrollado a contracorriente de las condiciones impuestas por el contexto del conflicto sirio, derivado de unas protestas populares que en el año 2011 inundaron las calles solicitando "pan, libertad y justicia social", así como la tan anhelada transición política, pero que pronto derivó en un conflicto internacionalizado dada la multiplicidad de actores estatales y no estatales interesados en mantener a flote sus intereses estratégicos en el país. En lo local, encontramos grupos de oposición al régimen de Bashar al-Asad calificados como "los rebeldes" pero que incluyen agrupaciones tanto de carácter laico como salafista-yihadista (entre los que destaca el autodenominado Estado Islámico, que irrumpiera en escena en el año 2013 y alcanzara su momento de mayor plenitud en el verano del año siguiente, cuando llegó a controlar ocho provincias de Siria e Iraq asentadas en las proximidades de los ríos Éufrates y Tigris). En lo regional, de manera directa o a través de sus milicias aliadas, Arabia Saudita, Irán y Turquía han intervenido en repetidas ocasiones en el escenario sirio, mientras que a nivel internacional tanto Rusia como Estados Unidos han brindado apoyo o establecido alianzas tácticas tanto con el régimen sirio el primero, como con los kurdos el segundo (recuérdese que, desde octubre del año 2015, las milicias de las Fuerzas Democráticas Sirias recibieron apoyo militar y logístico estadounidense para alcanzar el objetivo de eliminar al Estado Islámico). Para ahondar en el conflicto se recomienda, por mencionar tan sólo unos ejemplos: Álvarez-Ossorio, Ignacio (2016): Siria. Revolución, sectarismo y yihad, España, Catarata-Fundación Alternativas. Gutiérrez de Terán, Ignacio y Álvarez-Ossorio, Ignacio (2011): Informe sobre las revueltas árabes, España, Ediciones del Oriente y Mediterráneo. Kodmani, Basma y Legrand, Felix (2013): Empowering the Democratic Resistance in Syria, Paris, Arab Reform Initiative.

${ }^{5}$ El territorio es concebido como dador de vida, sostén del "buen vivir" (consigo mismo y con la comunidad, no equivale por lo tanto al consumo siempre insatisfecho del capitalismo sino la posibilidad de tener lo necesario, convivir en armonía con la naturaleza y con los demás seres humanos) y deidad del componente espiritual. Los

REIM № 27 (diciembre 2019)

ISSN: 1887-4460 
objeto y epicentro mismo de su lucha contra los métodos capitalistas que, a lo largo de los años, han causado desastres ecológicos devastadores. En el norte de Siria se da continuidad a un proyecto que supone no sólo una cuestión ética sino un modelo alternativo de desarrollo que ha costado la vida a cientos de sus promotores. No es casualidad que de cada árbol plantado en Kobane durante el año 2017, pendiera un letrero con el nombre de algún caído y que fuese su familia la encargada cuidarlo y mantenerlo vivo (Azeez, 2018). Se trataba de revivir el medio ambiente, pero también de reforzar los lazos de la jiyana kominal o vida comunal y, en resumen, de "liberar la vida" como había sugerido el emblemático líder kurdo Abdullah Öcalan.

Öcalan también escribió que para alcanzar dicho objetivo se requería de una "revolución radical de las mujeres", agentes sobre las que recae la responsabilidad de articular los principios del confederalismo y de engendrar "una revolución dentro de otra revolución" (Öcalan, 2013:51 y 59). Es por ello que, en este escrito, el trinomio mujer-vida-libertad (jin-jiyan-azadi, en kurdo) no sólo refiere a uno de los más populares eslóganes de la también llamada "Revolución de Rojava" sino que pone en evidencia la centralidad de la participación de las mujeres en la totalidad del proyecto pues, aunque cada uno de los pilares debe estar vinculado con los otros dos para desarrollarse completamente, se considera que la liberación de las mujeres es el punto de partida hacia la consolidación del confederalismo democrático de la FDNS.

En total consonancia con las propuestas del confederalismo de Rojava, la filósofa y activista Vandana Shiva afirma que "el capitalismo patriarcal se basa en la guerra contra la tierra, contra las mujeres y contra la vida [...] este sistema criminal es la convergencia de codicia, de acumulación y de extractivismo, pero también es el miedo a todo lo que está vivo y libre" (Korol, 2016). En este sentido, mujer-vida-libertad también representa una contestación al sistema criminal implementado en el norte de Siria, el mismo que se ha traducido en el debilitamiento de las relaciones comunales y de solidaridad, así como en la profundización de estructuras jerárquicas como el patriarcado y la dominación del hombre sobre la naturaleza.

Al promover la democratización de la política y de la economía, el confederalismo democrático ha dado lugar a que las mujeres que participan en él consideren ineludible su adscripción al sistema de comunas y cooperativas a través de las cuales se está creando un modelo sustentable de producción y, hasta ahora, ${ }^{6}$ el logro más representativo de este proceso, es decir, la creación de Jinwar, la única aldea ecológica de mujeres. En este sentido, el texto tiene como objetivo examinar los postulados teóricos que sustentan dicha participación, reconociendo en todo momento que el proyecto económico/ecológico de Rojava enfrenta una serie de dificultades que ponen en peligro su subsistencia teórica y práctica. Para tal efecto, se ha realizado una investigación documental que contempla tanto la obra de los ideólogos que han nutrido el discurso del confederalismo democrático como la información proporcionada por instituciones $u$ organizaciones presentes en el norte de Siria. Como se evidenciará, además de las amenazas externas, existen discrepancias o contradicciones que podrían debilitar internamente al confederalismo democrático, no obstante, tras siete años de trayectoria, la participación de las mujeres en este proyecto económico/ecológico ha servido de inspiración a otros movimientos emancipatorios afines a nivel mundial.

\section{La situación sobre el terreno}

El 1 de agosto del año 2018 fue identificado como "el día del sobregiro de la Tierra", aludiendo al hecho de que la humanidad ha agotado todos los recursos que la naturaleza puede renovar en un

pueblos son parte integrante del territorio, allí están sus raíces, sus padres, sus abuelos, sus ancestros (por ello lo llaman territorio ancestral). El lugar donde se desenvuelve toda la vida de la colectividad tiene una historia: cada espacio, cada curso de agua, cada cerro o cada monte tiene un nombre ligado a esa historia. Por el contrario, la cultura capitalista ve a la tierra como un recurso natural del que se puede obtener un lucro, a través de la explotación o sobre explotación, con la finalidad de maximizar las ganancias. (González et. al., 2019: 85 y 124-126).

${ }^{6}$ El periodo comprendido en este estudio abarca de julio de 2012 a agosto de 2019. 
año. A partir de ese día, estamos consumiendo lo equivalente a 1.75 Tierras $^{7}$. Sin importar que el impacto de los datos anteriores sea distinto de país a país, es indudable que cada ser vivo sobre la faz de la Tierra está siendo víctima de los efectos del calentamiento global y el cambio climático, fenómenos prácticamente irreversibles causados por un sistema capitalista que ha mutado puesto que, según el geógrafo y teórico social David Harvey, "antes se trataba de la acumulación, ahora de la desposesión de lo común" (Barranco, 2019). Con ello queda comprobado, una vez más, que la razón del beneficio económico del capitalismo es incompatible con la estabilidad ecológica del planeta dado que depende de la explotación irracional de sus recursos, así como de la generación de unos excedentes que no tienen como fin cubrir las necesidades básicas de la población ni mejorar sus condiciones de vida.

En el caso de los territorios que hoy administra la FDNS, el modelo económico capitalista fue introducido a partir de la década de $1950^{8}$ por un régimen nacionalista que excluyó política y socialmente a grupos étnicos como los kurdos, presentándolos incluso como una amenaza para la identidad árabe. Ese tipo de prácticas, intensificadas a partir de 1963 tras la llegada al poder del Partido Baaz, estarían acompañadas de proyectos "modernizadores" (industrialización de la agricultura, construcción de represas, impulso a la perforación petrolera y la minería, entre otros) que no fueron consultados con las poblaciones locales, principales afectadas por la reciente infraestructura o los consecuentes procesos de urbanización y migración económica, pero sobre todo por una nueva dinámica social que transgredió relaciones comunales y solidarias preexistentes, tales como la participación asamblearia y cooperación tanto en días de fiesta como en aquellos otros de necesidad, tiempos en los que no todo estaba valuado de forma monetaria. Adicionalmente, y para evitar la romantización de estas sociedades, conviene señalar que antes de la irrupción de los procesos de acumulación capitalista, eran cotidianas diversas formas de conservadurismo, así como relaciones jerárquicas y patriarcales que se agudizaron con la transición a dicho sistema económico.

En cuanto a Rojava, región sumamente fértil debido a que se localiza dentro del sistema fluvial de los ríos Éufrates y Tigris, el régimen sirio desarrolló una economía centralizada que la convirtió en el granero del país a través de prácticas como la siembra de monocultivos como trigo, frijol o algodón, crecidos a base de fertilizantes, pesticidas y otros químicos que deterioraron notablemente el entorno, a lo que se suma la prohibición gubernamental de sembrar árboles de cualquier especie. Asimismo, la naturaleza neocolonial del gobierno se aseguró de mantener explotada, pobre y dependiente a la región, cuyas materias primas eran procesadas en ciudades como Alepo, Homs o Hama y devueltas después para su consumo (Aguilar, 2017: 72).

\footnotetext{
${ }^{7}$ De acuerdo con los cálculos de la Organización No Gubernamental (ONG) Global Footprint Network, países como España, México, Egipto, Turquía, Arabia Saudita, Argelia o Marruecos, tienen un déficit ecológico de -150\%. Para más datos e iniciativas en marcha, puede consultarse Global Footprint Network: "Earht Overshoot Day", Global Footprint Network, 2018, disponible en https://www.footprintnetwork.org/our-work/earth-overshoot-day/ [consulta: 1 de diciembre de 2019], así como el de Earth Overshoot Day: “Earth Overshoot Day was July 29”, Overshoot Day, 2019, https://www.overshootday.org/ [consulta: 1 de diciembre de 2019],

${ }^{8}$ En estricto sentido, la introducción de Oriente Medio al sistema capitalista internacional se inició a partir de la segunda mitad del siglo XIX y se reforzaría con el inicio del periodo colonial; no obstante, se hace alusión a la década de 1950 considerando que la República Árabe Siria nació a la vida independiente en el año 1946 por lo que, a partir de esa fecha, la implementación de dicho sistema económico ya no era una imposición externa sino una decisión del nuevo régimen.
}

REIM № 27 (diciembre 2019) ISSN: $1887-4460$ 
Es necesario combinar la lucha por el medio ambiente con la batalla por una revolución social general.

Abdullah Öcalan

\section{La teoría y los documentos}

Con el objetivo de revertir la situación antes descrita (y aprovechando el favorable contexto proporcionado por las protestas populares del año 2011), el confederalismo democrático adoptó los fundamentos teóricos propuestos por Murray Bookchin, intelectual y activista libertario de quien Abdullah Öcalan se considera discípulo. Quizá su principal herencia al proyecto de Rojava sea la ecología social, ciencia que no sólo critica la separación entre la humanidad y la naturaleza, sino que intenta reconciliarlas dada su mutua interdependencia (Bookchin, 1999:101).

Desarrollada en la década de 1960 como respuesta a lo que Bookchin consideraba los fracasos de los proyectos revolucionarios del marxismo y el anarquismo, la ecología social se basa en la convicción de que todos los problemas ecológicos presentes se originan en problemas sociales profundamente arraigados (Bookchin, 2006:20), de modo que, tomando en consideración los modos de producción y consumo actuales (basados en la explotación de los individuos y de la naturaleza), resulta apremiante hablar no sólo de una economía capitalista sino también de una cultura capitalista, ambas sin límites morales, que aceleran un proceso de descomposición social al poner un precio a cualquier aspecto de la vida y, sobre todo, al fomentar una profunda alienación entre los seres humanos y la naturaleza o, en palabras de Vandana Shiva, un "apartheid ecológico".

Como resultado de las investigaciones antropológicas realizadas por Bookchin en torno a la relación entre las crisis ecológicas y los sistemas de jerarquía, el "comunalismo" sería propuesto como alternativa de organización social descentralizada, basada en principios democráticos y ecológicos (citado en Gerber y Brincat, 2018). En este sentido, en los territorios de la FDNS se ha considerado indispensable replantear la relación humanidad-naturaleza mediante la eliminación de relaciones jerárquicas y de toda noción de dominación del ser humano sobre la naturaleza y del ser humano sobre sí mismo. Para lograrlo, quienes protagonizan la "Revolución de Rojava" han dejado claro que la abolición del patriarcado y del capitalismo constituyen la única vía hacia el establecimiento de una sociedad justa, en la que las relaciones sociales y naturales sean concebidas de manera holística. Al respecto, Öcalan escribiría que "en el autogobierno, es necesaria una alternativa al sistema económico, uno que aumente los recursos de la sociedad en vez de explotarlos, de modo que satisfaga la multitud de necesidades de la sociedad" (Öcalan, 2011:26) $)^{9}$.

Las mujeres que participan en la construcción de un modelo económico/ecológico alternativo para la FDNS, parten de la consideración de que una sociedad ecológica no puede existir sin la emancipación de las mujeres, históricamente las primeras en experimentar diversas formas de opresión y exclusión socio-económica. En consecuencia, se requirió generar una mentalidad

\footnotetext{
${ }^{9}$ En este argumento también es posible reconocer la influencia de Immanuel Wallerstein, Michael Hardt y Antonio Negri en el pensamiento de Öcalan al sostener que las democracias representativas impiden tanto el auto-gobierno como la autonomía, razón por la cual no deberían considerarse democracias plenas pues excluyen a la población. Para profundizar a este respecto se recomienda: Arribas, Guillermo (2018): Transformación ideológica de Abdullah Öcalan. El movimiento kurdo y la confederación democrática, disponible en https://rojavaazadimadrid.org/transformacionideologica-de-abdullah-ocalan-el-movimiento-kurdo-y-la-confederacion-democratica/ [consulta: 20 de noviembre de 2019].
} 
libertaria capaz de articular alternativas ideológicas a los paradigmas dominantes y de sustentar el surgimiento de un movimiento por la libertad de la mujer, nació así Jineoloji. Traducido como "ciencia o estudio de las mujeres", tiene el propósito de superar las dicotomías de género que han servido para justificar relaciones de dominación, siendo el patriarcado su manifestación más acabada. Asimismo, busca visibilizar la participación que las mujeres han tenido en la construcción del cambio histórico-social, así como su contribución en la producción del conocimiento y las ciencias.

Jineoloji está presente en todos los aspectos y niveles de funcionamiento del confederalismo democrático. En el ámbito político, ha conseguido implantar el sistema hevserok o de liderazgos duales en todos los niveles de toma de decisiones, así como asegurar una cuota del $50 \%$ de mujeres en las organizaciones mixtas y establecido instituciones autónomas exclusivas de mujeres. En asuntos de seguridad y autodefensa, las Unidades de Protección de Mujeres (YPJ, por sus siglas en kurdo) han obtenido reconocimiento internacional y alentado la producción de análisis tendientes a dotar de una perspectiva de género el estudio de los conflictos y las teorías de la guerra $^{10}$. Por último, en el rubro socio-económico y ecológico resalta la labor de Yekitiya Star

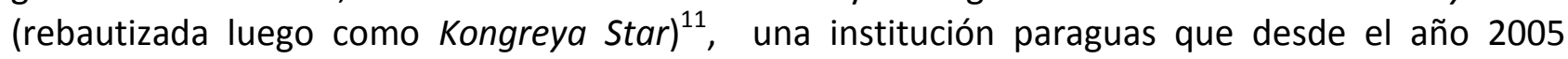
coordina la participación de las mujeres en decenas de organizaciones enfocadas a su desarrollo integral y autosuficiencia, destacando el papel de las Academias y Universidades. En octubre de 2017, por ejemplo, la Universidad de Rojava ${ }^{12}$ introdujo el programa de estudios en Jineoloji, dirigido a cualquier aspirante que haya completado la secundaria y que pretenda contribuir a la construcción de una sociedad democrática. Para lograrlo, el plan de estudios contempla cursos sobre la ruptura con el sistema capitalista y patriarcal, defensa personal, anatomía femenina, impartición de justicia, psicología, enfermería, desarrollo de sistemas comunales y agricultura avanzada en conexión con la ecología, entre otros ${ }^{13}$.

Sin duda, otro elemento de vital importancia para garantizar la participación de las mujeres en el proyecto económico/ecológico de la FDNS es la existencia del Contrato Social ${ }^{14}$, documento que en su Artículo 26 establece que "tendrán derecho a participar en régimen de igualdad en todos los ámbitos de la vida -político, social, cultural, económico, administrativo y otros- y a tomar decisiones relevantes para los asuntos que las conciernen". Asimismo, como ciudadanas de los territorios auto-administrados, tienen "el derecho a vivir en una sociedad ecológica sana" (Artículo 32) y, por lo tanto, la obligación de desempeñar un rol protagónico en la protección de la vida y el equilibrio ecológico (Artículo 76).

Amparadas con estas disposiciones, las participantes del confederalismo democrático colaboraron activamente en la formación de las primeras comunas de la FDNS. En el artículo 3 del documento titulado "El sistema interno de las comunas de Rojava" se define a la "comuna" como "la unidad social más pequeña de la sociedad y la más eficaz, establecida sobre la base de la participación directa en los pueblos y barrios, y que se ocupa de organizar y resolver las cuestiones de la vida

\footnotetext{
${ }^{10}$ Véase por ejemplo: Sjoberg, Laura (2013): Gendering Global Conflict: Toward a Feminist Theory of War, Nueva York, Columbia University Press.

${ }^{11}$ Unión Star y Congreso Star, respectivamente. Star en alusión a Ishtar, diosa mesopotámica de la fertilidad.

${ }^{12}$ Fundada en julio del año 2016 en la ciudad de Qamishli.

${ }^{13}$ El plan de estudios, con una duración de dos años, está disponible en el sitio oficial Jineoloji.org: “jineoloji”, 2019, disponible en https://jineoloji.org [consulta: 2 de diciembre de 2019].

${ }^{14}$ Véase en español en Rojava Azadi Madrid: "Contrato Social de la federación Democrática del Norte de Siria", marzo de 2018, disponible en https://rojavaazadimadrid.files.wordpress.com/2018/03/contrato-social-de-la-federaciondemocratica-del-norte-de-siria.pdf [consulta: 2 de diciembre de 2019].
}

REIM № 27 (diciembre 2019) ISSN: $1887-4460$ 
cotidiana de la sociedad" (Publicaciones Tev-Dem, 2014) ${ }^{15}$. Para Zeynep, una ingeniera originaria del Kurdistán turco, "la mujer es la tierra, la tierra es la base de la comuna, la comuna es la base de la sociedad", por ello trabaja arduamente en un proyecto de amplios terrenos de cultivo e invernaderos donde se siembra maíz, único en la región, "¡Maíz de Rojava!" declara a sus entrevistadores a quienes ha conquistado con tan sólo portar una playera donde se lee la frase "no soy normal" (Diagonal, 2016). Quizá sin saberlo, estas primeras participantes de la vida comunal estaban replicando el entusiasmo con que Silvia Federici ha exaltado las relaciones de producción comunal y las cooperativas, afirmando que la expansión del capitalismo se detiene e incluso es forzado a retroceder cuando los lazos comunales son más fuertes (citado en Gerber y Brincat, 2018).

Tekiliyen bi nan u xwey

(Lazos a través del pan y el sudor)

Dicho kurdo

\section{La práctica}

A mediados del año 2012, con la intensificación del conflicto en Siria, el aislamiento y la desfavorable situación económica que caracterizaba a Rojava supuso tanto una desventaja como la oportunidad ideal para volver a un comunalismo primitivo que se basara en formas tradicionales de producción pero que, estando fundamentadas en la solidaridad, supusieran asimismo el inicio de un modelo alternativo de desarrollo que coadyuvara a la emancipación de las mujeres y de la sociedad en su conjunto (Aguilar, 2017: 74). Considérese por ejemplo que, en Kobane, antes del año 2012, eran cosechadas 200 mil toneladas de centeno y 250 mil hectáreas eran utilizadas para el cultivo de frutas y verduras, mientras que en el año 2016 la producción de centeno se redujo en un $50 \%$ y la de frutas y verduras en un $15 \%$. Afrin, especializado en la producción de aceite de olivo gracias a los 18 millones de árboles con que contaba, cosechaba al menos 75 mil toneladas de aceitunas. En Cizire, aunque la producción agrícola de cereales, frutas y verduras también era importante, sobresalía la producción petrolera de al menos 90 mil barriles diarios en el año 2010, sin embargo, debido al embargo económico impuesto al trabajo comunitario de Rojava y a las dificultades técnicas derivadas del conflicto (destrucción de infraestructura), la población no ha sido capaz de usar más del $20 \%$ de sus recursos energéticos (citado en Lebsky, 2016). Sin duda alguna, la presencia del Estado Islámico contribuyó a agravar la situación económica de Rojava puesto que su paso por la región quedó marcado por la destrucción de las cosechas, la tala de árboles, el sacrificio indiscriminado del ganado, la destrucción de infraestructura y maquinaria, etc.

Como respuesta a estas condiciones, así como la llamada "Revolución de Rojava" traspasó las funciones estatales a la administración autónoma, los procesos productivos también fueron transferidos a la sociedad con el fin de "democratizar la economía", esto a través de mecanismos de descentralización tales como el trabajo cooperativo. Las tierras fueron socializadas ${ }^{16} \mathrm{y}$, con el apoyo de las comisiones económicas y de Kongreya Star, las mujeres de Rojava (kurdas, árabes,

\footnotetext{
${ }^{15}$ Por su parte, el Contrato Social define a la comuna como "la forma organizativa fundamental de la democracia directa... La Comuna funciona como una asamblea independiente en todos los niveles de toma de decisiones" (Artículo 48). Cada una de estas unidades sociales cuenta con una estructura básica que comprende una copresidencia, una comisión administrativa y un número variable de comités o comisiones (según las necesidades específicas de cada comuna) entre las cuales figuran las económicas y ecológicas.

${ }^{16}$ Aunque no se tienen reportes detallados por cantón o ciudad, se ha documentado que al menos en Serekaniye 2,500 hectáreas habían sido redistribuidas entre la población en el año 2015 (Knapp et. al., 2016:199). Las cifras recogidas a lo largo del texto han sido obtenidas de los informes o notas proporcionadas por las instituciones autónomas, organizaciones, informantes, periodistas o investigadores sobre el terreno. Es probable que exista un sesgo, sin embargo, al ser los únicos datos con los que se cuenta hasta el momento, han sido retomados incluso por textos académicos como el antes referenciado.
} 
siriacas y armenias, principalmente) iniciaron la formación de comunas y cooperativas agrícolas, ganaderas y de producción de alimentos con las cuales comenzaron a contribuir a la resistencia anticapitalista, así como a promover la incursión de más compañeras en actividades en las que tradicionalmente no participaban, rompiendo entonces con la situación de dependencia económica respecto a sus padres o esposos (Aguilar, 2017: 74).

El 19 de julio de 2012 fue establecida la Unión de Sociedades Cooperativas con el objeto de dar a conocer y desarrollar el concepto (Samir, 2018), propósito que vio frutos a partir del año siguiente cuando las primeras cooperativas fueron establecidas formalmente en la ciudad de Derik y luego en el resto del cantón de Cizire, donde las cooperativas ya habían plantado 50 mil árboles frutales para el año 2015 (Knapp et. al., 2016: 199). Por su parte, el Comité Económico de Mujeres fue creado en agosto del año 2015 con la finalidad de facilitar la formación de cooperativas exclusivas de mujeres (pero que pueden dar trabajo a algunos hombres, como en el caso de la cooperativa textil Warshin, por ejemplo), así como para apoyar su funcionamiento. El Comité recibe entre el $1 \%$ y $2 \%$ de las ganancias de cada cooperativa y aunque el resto se divide según las necesidades de cada una, generalmente el $50 \%$ de los beneficios se divide entre las participantes, el $25 \%$ es invertido y el resto se destina a cubrir las necesidades de la comuna, principalmente en lo que a servicios de salud y educación se refiere (Gupta, 2016).

Pese al entusiasmo que caracterizó los trabajos cooperativos iniciales, es necesario recordar que el primer invierno de la "Revolución de Rojava y sus mujeres" fue muy crudo, especialmente porque la escalada del conflicto sirio en el año 2013 supuso la pérdida de infraestructura básica (como los molinos que fabricaban pan, uno de los alimentos principales de la comunidad) y el agravamiento de la situación ecológica a causa de la tala de árboles cuya madera tuvo que ser utilizada como leña. A tales condiciones habría que sumar los efectos del cambio climático y de la sequía que asoló al país entre 2007 y 2011, considerada la peor en 60 años: altas temperaturas, desertificación, insuficiencia agrícola y alimentaria, principalmente (King, 2015: 153-154). Contrario a lo que pudiera suponerse, esta situación alentó los esfuerzos comunitarios y de cooperativas que improvisaron la construcción de nuevos molinos y refinerías e impulsaron tanto el comercio a pequeña escala como el cultivo de verduras y especias. Entonces como ahora la fiel compañera de Murray Bookchin, Janet Biehl, asegura que la subsistencia, la autonomía, el localismo y la sostenibilidad permanecen siendo los pilares centrales de la economía social de Rojava, con las cooperativas funcionando como núcleo de esta producción local basada en la subsistencia (citado en Cemgil y Hoffmann, 2016).

La preocupación por que el trabajo cooperativo respetara los principios de la ecología social quedó reflejada en algunas disposiciones del Contrato Social del año 2016, así como en el contenido de documentos oficiales que detallan el funcionamiento de las cooperativas. En el primer caso, el Artículo 11 establece que la FDNS "se basa en el principio de la colectivización de la tierra, el agua y los recursos energéticos [y] adopta los principios de la economía social y la industria ecológica", mientras que el Artículo 41 enfatiza que "la riqueza y los recursos naturales son de propiedad pública". En cuanto al sistema interno de las cooperativas, el Centro de Desarrollo de la Economía Social del Movimiento por una Sociedad Democrática (Tev-Dem) ha editado un folleto oficial titulado Reziknameya kooperatifa, xalen bingehin (Pautas para las cooperativas, principios básicos) ${ }^{17}$ que ya desde el primer apartado, denominado "Términos y condiciones", especifica que

\footnotetext{
${ }^{17}$ Véase el documento completo en inglés en Co-operation in Mesopotamia: “How do co-operatives work in Rojava?, mesopotamia.coop, s/f, disponible en https://mesopotamia.coop/how-do-cooperatives-work-in-rojava/ [consulta: 2 de diciembre de 2019]. Co-operation in Mesopotamia forma parte de la Solidarity Economy Association, una REIM № 27 (diciembre 2019)
} ISSN: $1887-4460$ 
la libertad y la equidad son principios básicos de la vida práctica y administrativa, con las mujeres tomando el lugar que les corresponde en todas las comisiones (administrativa, financiera, de seguimiento). Paulatinamente, el trabajo cooperativo se fue perfeccionando pasando de pequeños talleres y discusiones en torno a diversos enfoques organizativos, a un sistema de funcionamiento interno que establece, entre algunos de sus principales criterios, que: 1) La membresía es voluntaria y la retirada se pone a consideración de la Asamblea General. 2) El miembro activo es el que participa en las actividades de la cooperativa con sus esfuerzos mentales y físicos, mientras que el miembro financiero es aquel que participa solamente con dinero. 3) Las decisiones y proyectos serán implementados sólo si se obtiene el $60 \%$ de los votos emitidos. 4) Finalizado el año o el proyecto, una parte de las ganancias se destina a cubrir las necesidades de la cooperativa (compra de herramienta, reparaciones, etc.), otra se distribuye entre sus miembros en función de su trabajo y necesidades y, por último, otra parte se reserva para atender las necesidades de la comuna (salud, educación, electricidad, carreteras, etc.) 5) Existen mecanismos o protocolos ante el registro de pérdidas, el mal funcionamiento de la cooperativa o comportamientos poco éticos de sus miembros (robo, fraude, prácticas desleales, etc.), así como para evitar la formación de monopolios financieros. Desde sus inicios han estado en contra de la plusvalía, de modo que, por ejemplo: "la cooperativa agrícola vende productos a bajo costo a la cooperativa de ganado, que vende su leche a la cooperativa de procesamiento de productos lácteos. Ésta última vende su producto a la cooperativa comercial, que luego lo vende a la gente a un precio barato. Así se eliminan cinco intermediarios" (Deniz, 2017).

De manera complementaria, el trabajo educativo de las Academias sigue siendo prioritario para alentar a más mujeres a unirse al proyecto económico/ecológico de Rojava, por ejemplo: desde 2015 abrió sus puertas la primera Academia Ecológica en Cizire, mientras que la Academia de la Comuna Económica de la ciudad de Hasaka imparte cursos sobre Confederalismo Democrático, Modernidad Capitalista, Jineoloji, Economía de las Mujeres, Historia y funcionamiento interno de las cooperativas, entre otros (Ahmed, 2018).

El trabajo de las mujeres de la FDNS se ha convertido en un ejemplo de esperanza e inspiración alrededor del mundo ${ }^{18} \mathrm{y}$, aunque desde todas las geografías se han escuchado voces que intentar explicar las dimensiones que éste ha alcanzado, sus protagonistas son las más indicadas para exponer los cambios que ha generado. Por ejemplo, para Delal Afrin, jefa del Comité Económico

cooperativa británica cuyo propósito es apoyar el crecimiento de la economía solidaria. Co-operation in Mesopotamia tiene como objetivo fomentar la solidaridad económica internacional entre los movimientos cooperativos del Reino Unido y Europa con aquellos situados en Rojava y Bakur (este de Turquía). El sitio oficial del proyecto es: https://mesopotamia.coop

${ }_{18}$ Especialmente en América Latina, donde diversos pueblos originarios también reclaman el derecho a la autodeterminación y luchan por la defensa de sus territorios y el control de los recursos. Físicamente o con la ayuda de las tecnologías de la información y comunicación, las mujeres de Rojava han intercambiado aprendizajes y experiencias con movimientos que, tomando su ejemplo, replican procesos organizativos ante el patriarcado, el capitalismo y el Estado, tal es el caso del "Movimiento de los trabajadores rurales sin tierra" de Brasil o la lucha de las mujeres y los pueblos originarios de Bolivia y Wallmapu (territorio ancestral del pueblo mapuche) donde ya ha sido establecido el Comité de Solidaridad con Kurdistán de la Región Chilena y Wallmapu. En el caso del Movimiento Zapatista de Liberación Nacional (EZLN) en México, los acercamientos y el diálogo han sido constantes durante los últimos años, destacando momentos como el ocurrido el 6 de mayo del año 2015 en San Cristóbal de Las Casas (Chiapas), cuando en el marco del Seminario "El pensamiento crítico frente a la hidra capitalista" la activista kurda Havin Güneser pronunció un discurso de solidaridad del "pueblo de las montañas" al "pueblo de la selva". Igualmente reveladora resultó la publicación, en junio del año 2017, de la carta mediante la cual el Movimiento de Mujeres de Kurdistán expresara su apoyo a María de Jesús Patricio Martínez, candidata del Congreso Nacional Indígena a la presidencia de México. A nivel internacional, gracias al lanzamiento de la campaña Jin Rojava Diparezin o Women defend Rojava (agosto de 2019), decenas de organizaciones de mujeres han impulsado la creación de comités de solidaridad locales (en Madrid fue establecido el 9 de noviembre de 2019) o expresado su acompañamiento y admiración a las mujeres de Rojava. Entre estas organizaciones se encuentran, por ejemplo: Comunidad de paz de San José Apartadó (Colombia), The rules (Canadá), Rural solidarity (Benín), Better world (Camerún), Tarun Bharat Sangh (India), etc. 
de Mujeres de Kongreya Star, la importancia de cooperativas de mujeres es que: "los derechos de hombres y mujeres deben ser los mismos [...] la confianza de las mujeres se construye a través de la autosuficiencia, del conocimiento y entrenamiento que adquieren en la formación de cooperativas. Una sociedad que es capaz de organizar una economía donde las mujeres tengan roles productivos es símbolo de una sociedad madura" (Gupta, 2016). Por su parte, Nabila Mohammed, copresidenta de la Unión de Cooperativas de Cizire expresó que: "Existen muchos tipos de sociedades cooperativas, según las necesidades de cada región, y han demostrado que son la mejor solución contra la manipulación de los precios, la inflación y el monopolio" (Samir, 2018). Según los datos más actualizados que Co-operation in Mesopotamia ofrece (diciembre del año 2018), en el cantón de Cizire el $7 \%$ de la economía proviene del trabajo cooperativo y al menos el 3\% de las cooperativas de mujeres, contabilizándose éstas en alrededor de 55 con 7 mil integrantes, aproximadamente. ${ }^{19}$ La misma fuente señala algunas de las ciudades con presencia de cooperativas de mujeres (Tabla 1 ).

Tabla 1: Ciudades con presencia de cooperativas de mujeres

\begin{tabular}{|c|c|c|l|}
\hline Ciudad & $\begin{array}{c}\text { Número de } \\
\text { cooperativas }\end{array}$ & $\begin{array}{c}\text { Cooperativas } \\
\text { de mujeres }\end{array}$ & \multicolumn{1}{|c|}{ Nombre / Actividad } \\
\hline Qamishli & 29 & 6 & $\begin{array}{l}\text { Lilit / Panadería } \\
\text { Yekbun / Alimentos } \\
\text { Shiler / Lácteos } \\
\text { Dastar / Conservas } \\
\text { Tienda de productos comestibles } \\
\text { Cooperativa de cría de ovejas }\end{array}$ \\
\hline Derik & 8 & 1 & Adar / Panadería \\
\hline Tirbespiye & 8 & 1 & Espigas de trigo \\
\hline Derbisiye & 8 & 2 & $\begin{array}{l}\text { Demsal / Alimentos } \\
\text { Alimentos }\end{array}$ \\
\hline Hasaka & 8 & 3 & $\begin{array}{l}\text { Inanna / Alimentos } \\
\text { Ishtar / Panadería } \\
\text { Granja }\end{array}$ \\
\hline Til Temir & 3 & 1 & Panadería \\
\hline Raqqa & 1 & 1 & Fardos / Banco de alimentos \\
\hline Tabqa & 4 & 2 & $\begin{array}{l}\text { Casa de alimentos de invierno } \\
\text { Mujeres del Éufrates / Textiles }\end{array}$ \\
\hline
\end{tabular}

Fuente: Elaboración propia con datos del sitio oficial de Co-operation in Mesopotamia https://mesopotamia.coop/ [consulta: 30 de noviembre de 2019].

Conscientes del impacto que su trabajo ha generado, las participantes del confederalismo democrático decidieron llevar a cabo la "Primera Conferencia de Economía de Mujeres del norte de Siria" el 19 de junio del año 2017 en la ciudad de Qamishli. Bajo el lema "Las mujeres son la base de una economía justa", las asistentes reiteraron el objetivo de alcanzar la autosuficiencia económica a través de la multiplicación de cooperativas, la apertura de academias que prioricen la enseñanza de la economía social, el establecimiento de comités y oficinas encargadas de asuntos comerciales, el abasto de maquinaria agrícola, etc. El tema prioritario sigue siendo el de la

\footnotetext{
${ }^{19}$ El dato contrasta con el ofrecido por Mediya Serxwebun, representante del Comité Económico de Mujeres en Qamishli, que en junio de 2017 declarara la existencia de 50 cooperativas con participación de al menos 15 mil mujeres (Deniz, 2017).
} 
producción agrícola en general y la diversificación de los cultivos en particular; a este respecto, y luego de seis años de arduo trabajo, se ha logrado cosechar un sinnúmero de "nuevos" alimentos, entre los cuales destacan: lenteja, garbanzo, tomate, espinaca, olivo, cebolla, cacahuates, coliflor, berenjenas, pimiento, calabaza, etc. Dispuestas a replicar este logro en el mayor número de comunidades, aunque sin olvidar que el suelo quedó dañado tras décadas de monocultivo y uso de fertilizantes, las mujeres han construido plantas de compostaje en pueblos como Til Temir y Tirbespiye (cantón de Cizire) con la intención de garantizar la autosuficiencia alimentaria, pero sobre todo, de evitar la importación de sustancias químicas que agraven la situación de la tierra. Adicionalmente, adoptaron la técnica de la agroforestería, sistema orientado a mejorar la productividad de las tierras mediante la combinación deliberada de plantas con cultivos agrícolas o animales. Mediante este tipo de prácticas ecológicas se pretende contestar a las voces críticas que consideran imposible la reorganización de la economía sin depender de los métodos utilizados antes del año 2012 aunque, en efecto, el trabajo ecológico ha sido un proceso lento que también ha implicado la limpieza de extensas superficies donde decenas de minas antipersona habían sido dispersadas (Knapp et. al., 2016: 199).

Los avances que el proyecto económico/ecológico ha registrado hasta el momento no podrían comprenderse totalmente sin el acompañamiento solidario de cientos de internacionales que han apoyado las iniciativas lanzadas por las comisiones económicas de la FDNS, tales como The Rojava Plan que, entre otras, albergó la campaña Feed the Revolution - Organic Agriculture in Rojava. El objetivo era recabar 180, 000 euros que serían destinados a multiplicar proyectos enfocados a garantizar la suficiencia alimentaria, esto durante los meses de mayo y junio del año 2016. Desde principios de 2018 está en marcha una nueva iniciativa llamada Make Rojava Green Again operada por la Comuna Internacionalista de $\operatorname{Rojava}^{20}$ y los comités económico y ecológico del cantón de Cizire. La campaña comprende principalmente tres aspectos, a saber: 1) El establecimiento de una Academia Internacionalista donde se dé prioridad a un tipo de educación ecológica y de economía social o moral, 2) La puesta en marcha de múltiples proyectos de reforestación, incluida la de la Reserva Natural de Hayaka (cerca de la ciudad de Derik, Cizire) y 3) Servir de lugar de encuentro e intercambio de conocimientos entre activistas, científicos, expertos ambientalistas, etc. (Internationalist Commune of Rojava, 2018:11-13).

Finalmente, el análisis estaría incompleto si omitimos el tema del suministro de energía pese a que en este asunto no se tenga registro de una participación significativa de mujeres. Mantener la perspectiva ecológica en esta cuestión ha sido complicado debido a la dependencia de los generadores de diésel y a lo costoso de su mantenimiento, así como a las dificultades que supone la generación de energía a partir de fuentes renovables como el agua pues, pese a la existencia de hidroeléctricas como la de Tishrin, el suministro del recurso es constantemente interrumpido por el régimen turco, hecho que se suma al progresivo agotamiento de las reservas de agua subterránea en Rojava. En cuanto al petróleo, Hediye Yusuf (co-presidenta de la FDNS) opina que, aunque la revolución ecológica de Rojava acepta la inversión en proyectos privados ${ }^{21}$, las cooperativas que refinen el crudo deben ser propiedad colectiva y no individual, pues se trata de un recurso que pertenece a toda la sociedad (Gupta, 2016).

\footnotetext{
${ }^{20}$ Fundada en el año 2017.

${ }^{21}$ Si bien la revolución ecológica de Rojava no ha dejado de lidiar con el capitalismo, intenta ponerle un límite a través de las disposiciones contenidas en los artículos 41 a 43 del Contrato Social donde se establece que las inversiones en proyectos privados serán permitidas siempre y cuando no contradigan el interés común, respeten el equilibro ecológico y satisfagan las necesidades sociales. No obstante, cabe preguntarse en qué medida este tipo de disposiciones pudieran ser utilizadas para salvaguardar los privilegios de los propietarios de tierras que son alentados a invertir en los proyectos agrícolas de Rojava, alejando entonces la posibilidad de reemplazar esta práctica por la del comunalismo, tal como sugería Bookchin (Glioti, 2016).
} 
Sólo una confederación global de ciudades rebeldes nos puede llevar hacia una nueva sociedad racional que cumpla la promesa de una sociedad más humanitaria.

Debbie Bookchin

\section{Jinwar, la aldea ecológica de las mujeres}

Hasta ahora, el logro más significativo de la participación de las mujeres en el proyecto económico/ecológico de la FDNS es la creación de Jinwar, literalmente "el lugar donde viven las mujeres". Cercana a la ciudad de Qamishli, esta aldea no sólo forma parte del gran experimento democrático del Confederalismo de Rojava sino que supone un precedente en la región al representar un espacio libre de opresión que da evidencia de la vida comunal como alternativa a los modos de producción, consumo, alimentación y construcción de una modernidad capitalista que transgrede todo vínculo con la naturaleza.

Desde finales del 2016, la administración autónoma y diversas agrupaciones internacionales dedicadas a la defensa de los derechos de la mujer formaron el "Comité de la creación de Jinwar". Comenzaron a imaginar la estructura, organización y funcionamiento de la aldea que daría hogar a decenas de mujeres árabes, kurdas, armenias o circasianas que, muchas veces acompañadas de sus hijos, buscan opciones a los roles asignados por una la sociedad patriarcal, así como una oportunidad para rehacer sus vidas luego de haber perdido todo a consecuencia del conflicto. Jinwar se inauguró el 25 de noviembre de 2018, día internacional en contra de la violencia hacia las mujeres, con una infraestructura de alrededor de 50 edificios entre casas e instituciones (Heval, 2019), todos construidos con ladrillos de adobe, madera y otros productos que no generan daños al medio ambiente.

Abierta a la llegada de más mujeres, la aldea ecológica de Jinwar no requiere más que presentar la solicitud ante Kongreya Star o Mala Jin (Casa de la Mujer) ${ }^{22}$ y comenzar a trabajar en el desarrollo de la economía de subsistencia basada en la agricultura, la cría de animales, la siembra y cuidado de los árboles frutales que rodean el pueblo o los huertos que cada casa tiene derecho a cultivar. Asimismo, como parte del principio ecológico de la aldea, se propuso utilizar energía solar obtenida mediante baterías dispuestas en los tejados u otros sistemas con tecnología fotovoltaica, ello con la finalidad de reducir la dependencia del sistema hidroeléctrico y los combustibles fósiles.

Cada habitante puede formar parte del Consejo de Jinwar, participar en la planificación de la vida comunal y adquirir las responsabilidades que cada una desee asumir, incluida la vigilancia nocturna de la aldea (ningún visitante varón debe permanecer más tiempo del permitido). En Jinwar también persiste la preocupación por ofrecer educación a cada una de sus integrantes y, sobre todo, a niñas y niños que crecerán acostumbrados a las ideas promovidas por el confederalismo democrático y que, por lo tanto, son vistos como semillas que dentro de algunos años echarán las raíces de la sociedad moral por la que tanto se ha trabajado.

En la escuela "Madre Uveys" o en la Academia Jinwar se imparten cursos similares a los del resto de las Academias de Rojava, priorizando la discusión abierta, el desarrollo de las capacidades y los talentos de sus integrantes, así como su bienestar emocional. A ello coadyuva la gestión conjunta del comedor, la panadería Ashnan o las tiendas de frutas y verduras, el tiempo de recreación en el parque y los jardines, las tardes de lectura en la biblioteca, la planeación del museo donde serán

\footnotetext{
${ }^{22}$ Creada para la resolución de conflictos.
} 
exhibidos sus trabajos artesanales e incluso el manejo del dispensario Shifajin donde aprenden las propiedades de plantas medicinales. Vista en su totalidad, esta aldea ecológica de mujeres funge ya como modelo a replicar por toda la región e incluso en geografías lejanas donde, se sabe, las compañeras comparten aspiraciones y deseos de emancipación.

Como puede observarse, es el caso de Jinwar el que probablemente pretenda mostrarse como la mayor evidencia no sólo del cumplimiento sino incluso de la superación de las tesis que moldearon el proyecto del confederalismo democrático. Conviene recordar que, influenciado por las ideas de Marie Mies, Veronica Bennholdt-Thomsen y Claudia von Werlhof (1988) respecto a la concepción de las mujeres como "la primera colonia o la más antigua de la esclavitud", Öcalan elaboró el argumento de que las desigualdades sociales iniciaron en la era neolítica con el establecimiento de jerarquías de género, por lo que la historia de las mujeres es al mismo tiempo la historia del dominio masculino, reflejado también en la formación del Estado-nación y del sistema económico de explotación que lo acompaña ${ }^{23}$. Por ende, el asunto de la equidad de género es presentado no sólo como uno de los aspectos del proyecto de Rojava, sino como un desafío clave ante el objetivo final de transformar la realidad social. Todo ello hace comprensible el énfasis puesto en la reproducción de prácticas cotidianas en las que las mujeres sean entendidas como agentes activos en los procesos que crean la historia de los pueblos (citado en Şimşek y Jongerden, 2018), justamente como se nos relata respecto a Jinwar. Pese a ello, insistimos tanto en la cautela como en la imperiosa necesidad de no desvincular los progresos internos del confederalismo democrático de los constantes reacomodos políticos que tienen lugar en el escenario sirio, pues son éstos los que continúan enmarcando el desarrollo del proyecto de la FDNS y de sus mujeres. En otras palabras, no se debe perder de vista que el futuro de esta política de género desde abajo, depende en gran medida del reconocimiento de la lucha contrahegemónica en su conjunto (Şimşek y Jongerden, 2018).

\section{Los desafíos}

\section{Para las mujeres}

Consolidar un modelo económico/ecológico como el que las mujeres están impulsando en la FDNS exige mucho más que cargar un arma y, sobre todo, toma tiempo. Se trata de un proceso que continúa diseminándose de puerta en puerta y de té en té en las reuniones de las aldeas que se han incorporando a la administración autónoma con poblaciones que no necesariamente están convencidas de los beneficios del trabajo solidario, sea porque les parece demandante, complejo o simplemente porque no están dispuestas a renunciar al beneficio personal en pro del colectivo. Sirin Ibraham Ömer, del distrito de Hileli en Qamishli, afirmaba que "muchas [mujeres] están muy influenciadas por la lógica de Estado, no se ven a sí mismas como personas capaces de gestionar sus propios asuntos. Tienen muchos hijos y problemas en casa. Sus hijos están jugando en la calle en vez de ir a la escuela. Estamos preocupadas por eso. Si una familia no tiene ingresos, nosotras tenemos un comité para eso, para proporcionarles los alimentos básicos" (Knapp, 2014). Declaraciones como esta ponen en evidencia que pese a los cambios que se han generado en materia de equidad de género, las estructuras patriarcales permanecen profundamente arraigadas en el día a día de las mujeres de Rojava puesto que siguen siendo objeto de burlas al desempeñar

\footnotetext{
${ }^{23}$ Claramente este pensamiento también se encuentra en "El origen de la familia, la propiedad privada y el Estado" de Friedrich Engels, donde ya se sostiene que la opresión de la mujer comenzó con el advenimiento de la sociedad de clases, sin embargo, una diferencia importante entre la teoría de Öcalan sobre la opresión y la liberación de la mujer y la de Engels es su negación de factores socioeconómicos. Engels argumentaba que con la aparición de las clases sociales se impuso una división del trabajo que relegaba el trabajo femenino y su condición social a una posición secundaria. En cambio, en el pensamiento de Öcalan el énfasis se pone en cuestiones como la "mentalidad" y la "personalidad". La opresión de las mujeres se supone enraizada en las actitudes patriarcales que se transmiten de generación en generación y son interiorizadas por las mujeres. Para liberarse ellas mismas, las mujeres necesitan desaprender esas actitudes tanto como los hombres, y de esta forma hombres y mujeres se crean de nuevo (De Jong, 2015:21 y 24).
} 
trabajos "de hombres", como en el caso de Ronida Qajo y sus amigas, dedicadas al mantenimiento y arreglo de teléfonos celulares: "Quería prender mucho más, porque cada vez que lo intentaba, la gente me decía que soy mujer y que esta profesión es sólo para hombres" (Tmmo, 2018).

\section{Para el proyecto económico/ecológico}

A lo largo de los últimos siete años, la "Revolución de Rojava" ha coexistido con una serie de acontecimientos y actores que tratan de obstaculizar la concreción de su proyecto, situación que sus protagonistas prefieren considerar como una oportunidad de fortalecimiento interno gracias al proteccionismo forzado al que han sido orillados y que justifica perfectamente todos los mecanismos de autodefensa que practican, incluso en materia ecológica. Pese a ello, saltan a la vista las consecuencias ambientales del conflicto sirio, reflejadas sobre todo en la contaminación del aire, el suelo y el agua, así como en los poco visibles pero mortales efectos de los residuos del armamento utilizado, a saber: conchas de uranio empobrecido, metales pesados, explosivos, TNT, entre otros (Internationalist Commune of Rojava, 2018:89-90). En este sentido, es comprensible que para la FDNS las prioridades en el rubro ecológico sean, por ejemplo: la planeación de estrategias para reducir la contaminación del agua y el aire, solucionar la escasez y tratamiento del agua, manejar eficientemente la basura y otros desechos, garantizar el abasto de energía eléctrica, rediseñar una industria que satisfaga las necesidades de la población (incluyendo el abasto petrolero) pero desde una perspectiva ecológica, etc. Por supuesto, todas estas actividades requieren tanto de la llegada de financiamiento como del desarrollo de cierto tipo de habilidades que deben ser aprendidas con rapidez, exigencias que no siempre pueden ser satisfechas.

Además de las dificultades internas, en el ámbito regional tanto el Gobierno Regional del Kurdistán como el régimen turco han intentado detener el proyecto confederalista de Rojava mediante embargos $y$, más recientemente, a través de actos catalogados como "terrorismo ecológico". A partir del mes de junio del año 2019, agencias como ANF News, Syrian Democratic Times o The Washington Post reportaban diariamente que una serie de incendios provocados ${ }^{24}$ sobre el territorio administrado por la FDNS habían arrasado con al menos 40 mil hectáreas de cultivo, causado daños estimados en 19 mil millones de libras sirias, así como el alza en el precio en los granos y, seguramente, el incremento de la hambruna en un buen número de aldeas. La administración autónoma, con ayuda de la campaña Make Rojava Green Again y la Media Luna Roja Kurda, ha puesto manos a la obra al lanzar la iniciativa From Ashes We Rose con el objetivo de reunir al menos 10 mil euros que serán entregados directamente a las comisiones agrícolas de la FDNS. Lamentablemente, al tiempo que el dinero se recaudaba a cuentagotas, los incendios continuaban absorbiendo territorio y amenazando zonas petroleras y centrales de generación eléctrica cercanas.

La situación del agua no es menos alarmante. El régimen turco ha utilizado las represas del río Éufrates (especialmente la Ataturk y Karakaya) para reducir los niveles de agua que fluyen hacia los territorios de la FDNS, afectando la actividad agrícola, ganadera, la generación de energía y el consumo humano, todo ello al tiempo que continúa excediendo la extracción de aguas subterráneas. Como puede observarse, tanto el "terrorismo ecológico" como la llamada

\footnotetext{
${ }^{24}$ La orden de provocar los incendios pudo provenir tanto del régimen turco (y aliados locales) como del sirio, del que se sospecha debido a que, a principios del 2019, la administración autónoma anunció que no vendería granos al gobierno (MacAuley, 2019). Conviene recordar que, pese a las restricciones, la FDNS ha exportado e importado bienes a la región pues el Artículo 54 apartado 7 del Contrato Social dispone que "Cada región tiene derecho a establecer y desarrollar relaciones diplomáticas, económicas, sociales y culturales con los pueblos y países vecinos, siempre que no contradigan el Contrato Social".
}

REIM № 27 (diciembre 2019) ISSN: $1887-4460$ 
weaponization of water se han convertido en unas de las más eficientes herramientas de guerra en el intento de asfixiar el proyecto de confederalismo democrático en Rojava. Paradójicamente, a partir del año 2012, las prácticas del también llamado "hidro-terrorismo" en Siria han sido exclusivamente atribuidas al Estado Islámico, esto bajo el supuesto de que los regímenes estatales utilizan con menor frecuencia estrategias catalogadas como "crímenes de guerra" por instrumentos como la Convención sobre la prohibición de usar técnicas de modificación ambiental con fines militares u otros fines hostiles (1976) o la Convención de Ginebra y su Protocolo Adicional II (1977), relacionado con la protección de víctimas en conflictos armados no internacionales (King, 2015:156-158 y 165). Al no ser miembro firmante, el régimen turco ha manipulado los flujos de agua con mucha mayor libertad a modo de castigo colectivo contra la población de la FDNS lo que, bajo una lógica de estrategia política, le permite demostrar su poder, incrementar su autoridad y consolidar su posición sin la necesidad de atacar, ocupar o controlar militarmente la zona (Von Lossow, 2016:85).

Finalmente, es importante agregar que a pesar de que el tema ecológico constituye uno de los pilares del confederalismo democrático y es recurrentemente mencionado en el Contrato Social de la FDNS, el inestable contexto en que avanza el proyecto no deja espacio para una planeación sustentable a mediano y largo plazo. La noción de "equilibrio ecológico" se deja sin definir y no hay especificaciones en cuanto a cómo se determinará o bajo qué criterios -o de quien(Capitalism Nature Socialism, 2015:8).

\section{Para el confederalismo democrático de la FDNS}

Quienes desde fuera observan con desconfianza los propósitos, alcances y métodos del confederalismo democrático de la FDNS, el tema de la "idolización" de Abdullah Öcalan suele servir para reducir a una mera adoctrinación la profunda transformación ideológica, el análisis y la crítica que dicho proyecto ha impulsado. Se pasa por alto que, al menos discursivamente, el confederalismo privilegia el criticismo, la discusión, el consenso de la colectividad por sobre la voluntad individual y que, en palabras de Bookchin, "en una sociedad racional [...] los líderes no tendrán el poder de obligar a la gente a hacer lo que no desea hacer. Su única fuente de influencia es la persuasión. $Y$, sobre todo, ellos serán responsables ante el resto de la gente, esto es, sus actos estarán bajo vigilancia constante" (citado en Biehl, 2009:179-180). No obstante, como bien señala Janet Biehl, "paradójicamente las sociedades construidas de acuerdo con ideologías emancipatorias han resultado ser profundamente intolerantes" (Biehl, 2015) de modo que sólo el tiempo y los reacomodos geopolíticos en Siria podrán comprobar si el confederalismo democrático será capaz de aumentar el número de sus simpatizantes sin transgredir el derecho de los miembros de la sociedad a no afiliarse a sus instituciones; fomentar un tipo de educación que privilegie el análisis y la crítica y no uno que equivalga a un mero adoctrinamiento; respetar las diferencias y el derecho a disentir; demostrar ser eficiente más que complejo; superar conservadurismos o tradicionalismos que pongan en riesgo la libertad de tomar decisiones individuales; enfrentarse a los jefes tribales que se niegan a perder autoridad; transgredir las estructuras patriarcales y reconfigurar roles de género, entre otras cuestiones.

Los detractores del confederalismo democrático de Rojava también han fabricado situaciones que a la distancia son difíciles de comprobar y, por lo tanto, cumplen con la función de crear desconfianza y confusión. Uno de los ejemplos más recientes se dio a partir del mes de marzo del año 2019, cuando las instituciones autónomas se hicieron del control militar y administrativo de al menos una tercera parte del territorio sirio. En opinión de algunos investigadores, esta situación ha propiciado conflictos de poder entre la población árabe mayoritaria y los liderazgos kurdos debido a que no están implementando la misma legislación que en Rojava (prohibición de la bigamia, por ejemplo) o bien, a que las y los co-presidentes de consejos de mayoría árabe han depositado su confianza en sus pares kurdos sin recibir el mismo trato pues, incluso, son supervisados por miembros de la administración kurda (Tsurkov y al-Hassan, 2019). Datos como 
los anteriores contrastan con la información proporcionada, casi veinte días después, por el texto Kurds and Arabs in Northeast Syria: Power struggle or power sharing? de la investigadora Amy Austin Holmes y el periodista Wladimir van Wilgenburg quienes, a modo de respuesta ante apreciaciones que consideran "superficiales", afirman que kurdos y árabes han trabajado codo a codo, a sabiendas de que la cooperación interétnica -y de género- es crucial para la supervivencia de la administración del norte y este de Siria (Austin y van Wilgenburg, 2019). Aunque opuestas, ambas narrativas ayudan a pensar en las dificultades que enfrenta la continuación del proyecto autónomo en la República Árabe Siria: por un lado, si las aseveraciones de Tsurkov y al-Hassan resultaran ciertas, muy probablemente el Confederalismo de Rojava (sus instituciones administrativas y cuerpos de seguridad) se verá forzado a limar cualquier posible aspereza con los liderazgos locales, fricciones que, en todo caso, obedecerían a intereses político-territoriales opuestos antes que a diferencias puramente étnicas o religiosas. En segundo lugar, si quienes han ofrecido un relato más fiel a la realidad sobre terreno son Austin y van Wilgenburg, resulta urgente reconocer y dimensionar los alcances de una propaganda cuya finalidad, claramente, es empañar los logros y frenar la divulgación de un poderoso proyecto político, económico, social y ecológico alternativo en el Oriente Medio ${ }^{25}$.

Lento, pero avanza

\section{Conclusión}

Desde hace varios años, hay quienes han asegurado que "Rojava se parece a un león herido perseguido por un grupo de hienas. El león tiene pocas posibilidades de ganar, pero luchará hasta el último suspiro" (Lebsky, 2016). Aquellos que se inclinen por aceptar la metáfora, también deberán reconocer que esta lucha y sus protagonistas insisten en transformar la realidad proponiendo formas alternativas de pensamiento y acción. Así parecen comprobarlo ejemplos como el de las personas que fueron desplazadas por la fuerza del cantón de Afrin tras la operación militar "Rama de Olivo" ${ }^{26}$, quienes han logrado convertir en jardines los campamentos y vecindarios semi-destruidos a los que llegaron a asentarse en la región de Shehba, al norte de Alepo. En la comuna "Jardines de Rojava" la producción ha eliminado la necesidad de importar alimentos pues, además de árboles y flores, se han sembrado peras, granadas, higos, uvas, pistaches, nueces, perejil, verduras e incluso menta para "esparcir la fragancia de los campos" (ANHA, 2019).

Incluso si se prefiere la cautela, es imposible negar la "victoria parcial" del proyecto económico/ecológico de Rojava, impulsado en buena medida por sus mujeres. Parcial porque aún queda un largo camino por recorrer y decisiones que tomar respecto a por lo menos dos posibles rutas para el mediano y largo plazos. La primera, tomando en cuenta la coyuntura local, regional e internacional, tiene que ver con la probabilidad de que el pragmatismo militar mostrado por la FDNS sea complementado con un pragmatismo político que tenga como objetivo establecer canales de diálogo con el régimen sirio y sus aliados puesto que, ante los más recientes

\footnotetext{
${ }^{25}$ Lo mismo sucede cuando se indaga la conducta del Partido de Unión Democrática (PYD) y de las Unidades de Protección Popular (YPG) con los sectores de población críticos al confederalismo democrático. Mientras Informes de Amnesty International, Human Rights Watch o el International Crisis Group intentan documentar y dejar registro de un sinnúmero de abusos, violaciones, desapariciones, arrestos injustificados, malos tratos, asesinatos, desplazamientos forzados, demoliciones, etc., los representantes de la administración, miembros del PYD y activistas de todo el mundo niegan la validez de tales aseveraciones (Leezenberg, 2016:681-682 y 687).

${ }^{26}$ Ofensiva perpetrada por el régimen turco y milicias sirias aliadas. Iniciada el 20 de enero del 2018 y completada el 18 de marzo del mismo año, cuando aseguraron el control completo del cantón.
}

REIM № 27 (diciembre 2019) ISSN: $1887-4460$ 
reacomodos geopolíticos al interior del país ${ }^{27}$, muy probablemente de dichos canales dependa su capacidad para trascender al conveniente contexto que lo vio nacer y echar raíces ${ }^{28}$. La segunda posible ruta puede estar relacionada con la decisión de romper todo diálogo y negociación con el gobierno central, tal como lo han hecho movimientos autonómicos hermanados ideológicamente al Confederalismo de Rojava. Aunque lento, este experimento puede replicarse exponencialmente y brindar una nueva evidencia de lo que en las montañas del sureste mexicano llaman "una de tantas semillas de las que nacerán otros mundos" (Subcomandante Insurgente Moisés, 2019).

A nivel interno e ideológico, es probable que la participación de las mujeres en el proyecto económico/ecológico de la FDNS no se apegue al pie de la letra a su propia teoría, cuestión que en todo caso es más que comprensible en la trayectoria de cualquier proyecto que se identifique como libertario o emancipatorio, máxime si desde sus inicios ha sostenido que la historia está en el día a día, o lo que es lo mismo, que la práctica va moldeando la teoría y no viceversa, como en las ciencias positivistas que crean una dicotomía entre las sociedades y su propia historia.

La fórmula mujer-vida-libertad da cuenta de las etapas en que se va tejiendo la vida colectiva: parte del trabajo cooperativo de sus protagonistas, mujeres y hombres que confrontan un sistema caracterizado por la acumulación, el despojo, la desigualdad, la alienación hombre/mujernaturaleza, la destrucción y la muerte. Dicha confrontación es radical en tanto que busca trascender la teoría e implementar múltiples esfuerzos creativos para transformar la realidad y luchar por la vida, propiciado efectos emancipatorios irreversibles.

\section{Referencias}

AGUILAR, Erika. (diciembre 2017): “Ecofeminismo en Rojava: hacia la construcción de un modelo alternativo de desarrollo económico en el territorio sirio del Kurdistán", Revista Ecología Política. Cuadernos de debate internacional, 54, pp. 72-76.

AHMED, Ihsan: "Rojava holds co-operatives training curse", Aboriya Civaki, Trad. Co-operation in Mesopotamia, 7 de noviembre de 2018, disponible en https://mesopotamia.coop/rojava-holds-cooperative-training-course/ [consulta: 18 de julio de 2019].

ÁLVAREZ-OSSORIO, Ignacio. (2016): Siria. Revolución, sectarismo y yihad, España, CatarataFundación Alternativas.

ANF NEWS: "Mazlum Abdi announces restructurating of SDF", ANF News, 24 de agosto de 2019, disponible en https://anfenglish.com/rojava-syria/mazlum-abdi-announces-restructuring-of-sdf$\underline{37145}$ [consulta: 26 de agosto de 2019].

ANHA HAWAR NEWS AGENCY: "Camps are changed to gardens", ANHA Hawar News Agency, 15 de julio de 2019, disponible en

https://www.hawarnews.com/en///haber/camps-are-changed-to-gardens-

h10266.html?fbclid=IwAR2-ugUpLVuq1Yr8bGcqiylnaiVZpl5qzMicZ3hia4 F4m17Rwjaw58kbmE [consulta: 15 de julio de 2019].

AUSTIN HOLMES, Amy y VAN WILGENBURG, Wladimir: "Kurds and Arabs in Northeast Syria: Power struggle or power sharing?", The National Interest, 11 de agosto de 2019, disponible en https://nationalinterest.org/feature/kurds-and-arabs-northeast-syria-power-struggle-or-powersharing-72281?fbclid=IwAROC-SBdZXHGgvUoj9yiVyWHEQk43IBLp8-9QqkG7hnEvEXT odWoA8xc I [consulta: 12 de agosto de 2019].

\footnotetext{
${ }^{27}$ El control de la mayor parte del territorio por el gobierno de al-Asad o el acuerdo turco-estadounidense para establecer una "zona segura" en el noreste de Siria (alcanzado a principios del mes de agosto de 2019), por ejemplo.

${ }^{28}$ El 24 de agosto de 2019 el Comandante General de las fuerzas de autodefensa de la FDNS, Mazlum Abdi, realizó un llamado al gobierno del presidente Bashar al-Asad para entablar un diálogo que los conduzca a una solución basada en el reconocimiento de la administración autónoma y de los derechos legítimos del pueblo kurdo en Siria. Asimismo, durante la conferencia "Garantizar la estabilidad después del fin del terrorismo", se discutieron los éxitos militares y políticos, así como las deficiencias y debilidades que ponen en jaque la seguridad y estabilidad de una Siria libre y unida (ANF, 2019).
} 
ARRIBAS, Guillermo. (2018): Transformación ideológica de Abdullah Öcalan. El movimiento kurdo y la confederación democrática, disponible en

https://rojavaazadimadrid.org/transformacion-ideologica-de-abdullah-ocalan-el-movimientokurdo-y-la-confederacion-democratica/ [consulta: 20 de noviembre de 2019].

AZEEZ, Hawzhin: "La cuestión ecológica: el fundamento del Confederalismo Democrático", Cooperation Mesopotamia, Trad. Rojava Azadi Madrid, 11 de diciembre de 2018, disponible en https://rojavaazadimadrid.org/la-cuestion-ecologica-el-fundamento-del-confederalismodemocratico/?fbclid=IwAR1prdnfTkQvQrrKI95RfTKbv98qRUDISKdELm062hOI MtzS dph3b275M [consulta: 4 de julio de 2019].

BARRANCO, Justo: "David Harvey: Construimos ciudades para que la gente invierta en vez de para que viva", La Vanguardia, 19 de agosto de 2019, disponible en https://www.lavanguardia.com/cultura/20190819/464143674196/construimos-ciudades-paraque-la-gente-invierta-en-vez-de-para-queviva.html?fbclid=IwAR2o0QjTGxHHYHOhpkXjcuGnb9X FZ 2K4ieqT85taB5p4S9qm70HihDZTE [consulta: 20 de agosto de 2019].

BIEHL, Janet. (2009): Las políticas de la ecología social. Municipalismo libertario, Barcelona, Virus editorial.

BIEHL, Janet: "Paradoxes of a liberatory ideology", Ecology or Catastrophe, 22 de noviembre de 2015, disponible en http://www.biehlonbookchin.com/paradoxes-liberatory-ideology/ [consulta: 26 de noviembre de 2019].

BOOKCHIN, Murray. (1999): La Ecología de la Libertad. El surgimiento y la disolución de la jerarquía, Trad. Marcelo Gabriel Burrello, Madrid, Nossa y Jara Editores/Colectivo Los Arenalejos. BOOKCHIN, Murray. (2006): Social Ecology and Communalism, Oakland, AK Press.

CAPITALISM NATURE SOCIALISM. (2015): "Rojava", Capitalism Nature Socialism, 26-1, pp.1-15. https://doi.org/10.1080/10455752.2015.1006948

CEMGIL, Can y HOFFMANN, Clemens: "The 'Rojava Revolution' in Syrian Kurdistan: A model of development for the Middle East?", IDS Bulletin, 3 de mayo de 2016, disponible en: https://bulletin.ids.ac.uk/idsbo/article/view/2730/2568 [consulta: 10 de julio de 2019] DOI: https://doi.org/10.19088/1968-2016.144

CO-OPERATION IN MESOPOTAMIA: "How do co-operatives work in Rojava?, mesopotamia.coop, s/f, disponible en https://mesopotamia.coop/how-do-cooperatives-work-in-rojava/ [consulta: 2 de diciembre de 2019].

DE JONG, Alex. (junio 2015): “¿De apisonadora estalinista a mariposa libertaria? La evolución ideológica del PKK", Viento Sur, 140, pp. 5-37.

DENIZ, Welat: "Las mujeres de Rojava celebrarán la primera conferencia sobre economía de las mujeres de Siria del norte", Trad. Rojava Azadi Madrid, 7 de julio de 2017, disponible en https://rojavaazadimadrid.org/las-mujeres-de-rojava-celebraran-la-primera-conferencia-sobreeconomia-de-las-mujeres-de-siria-del-norte/ [consulta: 25 de noviembre de 2019].

DIAGONAL: "Rojava: la revolución de las mujeres", Diagonal, 19 de abril de 2016, disponible en https://www.diagonalperiodico.net/global/30021-rojava-la-revolucion-mujeres.html [consulta: 5 de julio de 2019].

EARTH OVERSHOOT DAY: "Earth Overshoot Day was July 29", Overshoot Day, 2019, https://www.overshootday.org/ [consulta: 1 de diciembre de 2019].

GERBER, Damian y BRINCAT, Shannon. (2018): “When Öcalan met Bookchin: The Kurdish Freedom Movement and the Political Theory of Democratic Confederalism, Geopolitics.DOI: https://doi.org/10.1080/14650045.2010.1508016 
GLIOTI, Andrea: "Rojava: A libertarian myth under scrutiny", Al-Jazeera, 5 de agosto de 2016, disponible en https://www.aljazeera.com/indepth/opinion/2016/08/rojava-libertarian-mythscrutiny-160804083743648.html [consulta: 25 de noviembre de 2019].

GLOBAL FOOTPRINT NETWORK: “Earht Overshoot Day”, Global Footprint Network, 2018, disponible en https://www.footprintnetwork.org/our-work/earth-overshoot-day/ [consulta: 1 de diciembre de 2019],

GONZÁLEZ, Ana; KATZ, Mariana; MENDOZA, Angélica y ROMERO, Luis (2019): Derechos de los pueblos originarios y de la Madre Tierra. Una deuda histórica, Ciudad autónoma de Buenos Aires, CLACSO-Instituto de Investigaciones Gino Germani.

GUPTA, Rahila: "Women's co-operatives in Rojava”, Co-operation in Mesopotamia, marzo de 2016, disponible en https://mesopotamia.coop/womens-co-operatives-in-rojava/ [consulta: 17 de julio de 2019].

GUTIÉRREZ DE TERÁN, Ignacio y ÁLVAREZ-OSSORIO, Ignacio (2011): Informe sobre las revueltas árabes, España, Ediciones del Oriente y Mediterráneo.

HEVAL, Rûmet: "Cómo construimos la aldea de mujeres de Jinwar en Rojava", Komun Academy, Trad. Kurdistán América Latina, 7 de enero de 2019, disponible en: http://kurdistanamericalatina.org/como-construimos-la-aldea-de-mujeres-jinwar-en-

rojava/?fbclid=IwAR1SAaPIIY1jywRCwRk3qHcZOn7A7xgx70ee9kILPIW-oHVIPih5vEpSkZo [consulta: 3 de julio de 2019].

INTERNATIONALIST COMMUNE OF ROJAVA. (2018): Make Rojava Green Again, London, Calverts Ltd.

JINEOLOJI.ORG: "jineoloji”, 2019, disponible en https://jineoloji.org [consulta: 2 de diciembre de 2019].

KING, Marcus D. (2015): "The Weaponization of Water in Syria and Iraq", The Washington Quarterly, 38:4, pp. 153-169. DOI: https://doi.org/10.1080/0163660X.2015.1125835

KODMANI, Basma y LEGRAND, Felix. (2013): Empowering the Democratic Resistance in Syria, Paris, Arab Reform Initiative.

KOROL, Claudia: "Tenemos que reparar este sistema roto: Vandana Shiva”, Biodiversidad LA, 13 de julio de 2016, disponible en

http://www.biodiversidadla.org/Documentos/Tenemos que reparar este sistema roto Vandan a Shiva?fbclid=IwAR1IUhCmkd1BiDsM8W8PWygrOcuHXDdxpUrGWyHec8AniCiG0GrAsFbaz3U [consulta: 1 de agosto de 2019].

KNAPP, Michael; FLACH; Anja y AYBOGA, Ercan (2016): Revolution in Rojava. Democratic Autonomy and Women's Liberation in Syrian Kurdistan, Janet Biehl (Trad.), UK/USA, Pluto Press. DOI: https://doi.org/10.2307/j.ctt1gk07zg

KNAPP, Michael: "Democratic Autonomy in Rojava", New Compass. Ideas for a rational and free society, Trad. Janet Biehl, 10 de octubre de 2014, disponible en http://newcompass.net/articles/revolution-

rojava?fbclid=IwAR2tOhATb05P8aop3V47FzfENpoVLrk toUJ OEon j4wWqYwQc50zL8ylg

[consulta: 5 de julio de 2019].

LEBSKY, Maksim: "The economy of Rojava", Co-operation in Mesopotamia, 17 de marzo de 2016, disponible en https://mesopotamia.coop/the-economy-of-rojava/ [consulta: 14 de julio de 2019].

LEEZENBERG, Michiel (2016): "The ambiguities of democratic autonomy: the Kurdish movement in Turkey and Rojava", Southeast European and Black Sea Studies, 16:4, pp. 671-690. DOI: https://doi.org/10.1080/14683857.2016.1246529

MAC AULEY, Lacy: "Burnt Farm Fields Are Economic Terrorism", Syrian Democratic Times, 21 de junio de 2019, disponible en http://www.syriandemocratictimes.com/2019/06/21/burnt-farmfields-are-economic-terrorism/ [consulta: 26 de junio de 2019].

MIES, Marie; BENNHOLDT-THOMSEN, Veronica y VON WERLHOF, Claudia (1988): Women: the last colony, London, Zed Books.

ÖCALAN, Abdullah (2011): Democratic Confederalism, Londres y Colonia, Transmedia Publishing. 
ÖCALAN, Abdullah (2013): Liberating Life: Woman's Revolution, Cologne, International Initiative Edition in cooperation with Mesopotamian Publishers, Neuss.

PUBLICACIONES TEV-DEM: "The internal system of the communes in Rojava", Pundicity Informed Opinion \& Review, Trad. Aymenn Jawad Al-Tamimi, 17 de abril de 2018, disponible en http://www.aymennjawad.org/2018/04/the-internal-system-of-the-communes-in-rojava [consulta: 1 de julio de 2019].

ROJAVA AZADI MADRID: "Contrato Social de la federación Democrática del Norte de Siria", marzo de 2018, disponible en https://rojavaazadimadrid.files.wordpress.com/2018/03/contrato-socialde-la-federacion-democratica-del-norte-de-siria.pdf [consulta: 2 de diciembre de 2019].

SAMIR, Ahmed: "Las cooperativas están echando raíces en el norte de Siria", Kurdistán América Latina, Trad. Rojava Azadi, 3 de enero de 2018, disponible en: http://kurdistanamericalatina.org/las-cooperativas-estan-echando-raices-en-el-norte-desiria/?fbclid=IwAR3D5gHC5p30QaJeVxVezdIz-EBe0oxch8QnPZGMOxLk3miTqGOOWHCVYGY [consulta: 9 de julio de 2019].

SJOBERG, Laura (2013): Gendering Global Conflict: Toward a Feminist Theory of War, Nueva York, Columbia University Press.

ŞIMŞEK, Bahar y JONGERDEN, Joost (2018): “Gender Revolution in Rojava: The Voices beyond Tabloid Geopolitics", Geopolitics.DOI:

https://doi.org/10.1080/14650045.2018.1531283

SUBCOMANDANTE INSURGENTE MOISÉS: "Comunicado del CCRI-CG del AZLN. Y rompimos el cerco", Centro de medios libres, 17 de agosto de 2019, disponible en: https://www.centrodemedioslibres.org/2019/08/17/comunicado-del-ccri-cg-del-ezln-y-rompimosel-cerco/?fbclid=IwAR2aQ6FNmDkpNFqc25ermzraitn-uMdKgSVpkKQIOujPVoBEq6n5Yv8ms8A [consulta: 19 de agosto de 2019].

TMMO, Fansa: "Women's projects in Rojava - The rality and challenges", Buyer, Trad. Cooperation in Mesopotamia, 15 de febrero de 2018, disponible en

https://mesopotamia.coop/womens-projects-in-rojava-the-reality-and-challenges/ [consulta: 20 de julio de 2019].

TSURKOV, Elizabeth y AL-HASSAN, Esam: "Kurdish-Arab power struggle in Northeastern Syria", Carnegie Endowment for International Peace, 24 de julio de 2019, disponible en: https://carnegieendowment.org/sada/79542?mkt tok=eyJpljoiTUdKaVIXSTJZV1psTm1ZeCIsInQiOi JRSFwvXC9mbGFtNER4eVlyajJvZGFjeGFcL1INV05McWhQMGZzMWJsdE52STIOM2ZtNXhBRktycDFH cVZRVVZtaIRVQXduQ0h4SWJBQWgrM1RjYkJZUUc3OVwvMOZsOFFRNmIFY1BqaVwvcTIXcithSmNYe IpLTUYOUHJTOFNIZEXSCTdOIn0\%3D [consulta: 25 de julio de 2019].

VON LOSSOW, Tobias (2016): "The Rebirth of Water as a Weapon: IS in Syria and Iraq", The International Spectator, 51:3, pp. 82-99. DOI:

https://doi.org/10.1080/03932729.2016.1213063 